\title{
Yersinia bercovieri
}

National Cancer Institute

\section{Source}

National Cancer Institute. Yersinia bercovieri. NCI Thesaurus. Code C86854.

A species of facultatively anaerobic, Gram negative, rod shaped bacteria in the phylum Proteobacteria. This species is motile, positive for urease, ornithine decarboxylase, and pyrazinamidase and negative for indole, beta galactosidase, citrate, and oxidase. It is able to ferment sucrose, fucose, cellobiose, and xylose but not rhamnose, melibiose, or sorbose. Y. bercovieri is found in many environments and is not a known pathogen. 